\title{
Pengaruh Bauran Ritel Terhadap Keputusan Belanja Ulang Di Niagara Swalayan Bukittinggi
}

\author{
Widi Nugraha', Fhajri Arye Gemilang ${ }^{1,}$ Arina Fransiska ${ }^{2}$ \\ ${ }^{1}$ Universitas Fort De Kock Bukittinggi, Indonesia \\ ${ }^{2}$ Universitas Islam Negeri Imam Bonjol Padang, Indonesia \\ widinugraha@fdk.ac.id, ,fhajri.gemilang@gmail.com,, arinafransiska@uinibac.id
}

\begin{abstract}
The purpose of this research is to analyze the effect of retail mix on the repeat purchase decision in Niagara Supermarkets Bukittinggi. The population in this research are all consumers who shopped in Niagara Supermarkets and domiciled in Bukittinggi city and its surroundings. To determine the size of the sample by using Cochran formula. The number of samples in the research are 127 peoples. The sampling technique use purposive sampling technique. The analytical tool use the path analysis trimming model.

Retail Mix simultaneously influence the repeat purchase decisions in Niagara Supermarkets Bukittinggi. Customer service influence the repeat purchase decisions in Niagara Supermarkets Bukittinggi. Store design and display does not influence the repeat purchase decisions in Niagara Supermarkets Bukittinggi. Communications mix influence the repeat purchase decisions in Niagara Supermarkets Bukittinggi. The location does not influence the repeat purchase decisions in Niagara Supermarkets Bukittinggi. Merchandise assortment does not influence repeat purchase decisions in Niagara Supermarkets Bukittinggi. Pricing influence the repeat purchase decisions in Niagara Supermarkets Bukittinggi.
\end{abstract}

Keywords: Retail Mix and Repeat Purchase Decision

\section{Pendahuluan}

Bukittinggi di sumatera barat merupakan suatu kota yang cukup mempunyai potensi untuk perkembangan ritel modern, hal ini disebabkan oleh kota Bukittinggi merupakan kota wisata yang di huni masyarakat / penduduk asli atau pendatang yang mulai terbiasa dengan kehidupan kota yang biasanya di huni oleh suami istri yang kedua - keduanya bekerja sehingga mereka memerlukan ritel modern yang menyediakan kebutuhan mereka yang bisa di beli selepas pulang kerja yaitu jam 5 sampai dengan malam yang biasanya pada jam seperti ini ritel tradisional sudah tutup.

Swalayan merupakan suatu sarana berbelanja dengan tawaran berbagai jenis produk dari berbagai produsen untuk memenuhi kebutuhan dan keinginan konsumen. Sampai saat ini di kota Bukittinggi ada beberapa ritel modern yang bisa dikatakan sebagai swalayan yaitu Niagara Swalayan sendiri, Toko Kue Budiman, Masyitah Swalayan dan Ramayana Supermarket Bukittinggi yang berada di bawah payung Ramayana Lestari Sentosa Tbk. Sebelumnya di Kota Bukittinggi sudah ada juga beberapa swalayan seperti DA Mulia yang sekarang menjadi minimarket karena tempatnya yang jauh lebih kecil dari sebelumnya dan Anatama Swalayan yang berada di jln. Sutan Syahrir tetapi sekarang sudah tutup karena penulis sendiri tidak menemukan swalayan ini di jalan yang di maksud. Bukittinggi merupakan salah satu kota di Indonesia yang tidak memberikan izin masuk kepada peritel nasional seperti Indomaret dan Alfamart, sampai sekarang peritel nasional yang ada di Bukittinggi hanya Ramayana Supermarket yang berada di Plaza Bukittinggi.

Data Jumlah Pelanggan Niagara Swalayan Bukittinggi Oktober 2015 - Mei 2016 dapat dilihat di Tabel 1

Tabel 1. Jumlah Pelanggan Niagara Swalayan Bukittinggi Oktober 2015 - Mei 2016

\begin{tabular}{|c|c|c|c|c|c|}
\hline No & Bulan & Tahun & $\begin{array}{c}\text { Jumlah } \\
\text { Pelanggan }\end{array}$ & Perubahan & Prosentase \\
\hline 1 & Oktober & 2015 & 58.529 & - & - \\
\hline
\end{tabular}




\begin{tabular}{|c|c|c|c|c|c|}
\hline 2 & November & 2015 & 57.268 & -1261 & $2,2 \%$ \\
\hline 3 & Desember & 2015 & 60.432 & +3164 & $5,2 \%$ \\
\hline 4 & Januari & 2016 & 59.765 & -667 & $1,1 \%$ \\
\hline 5 & Februari & 2016 & 57.285 & -2480 & $4,3 \%$ \\
\hline 6 & Maret & 2016 & 56.367 & -918 & $1,6 \%$ \\
\hline 7 & April & 2016 & 60.190 & +3823 & $6,3 \%$ \\
\hline 8 & Mei & 2016 & 60.156 & -34 & $0,05 \%$ \\
\hline
\end{tabular}

Sumber : Manajemen Niagara Swalayan Bukittinggi

( Oktober 2015 - Mei 2016)

Data Tabel 1 mengindikasikan bahwa 8 bulan terakhir yaitu dari bulan Oktober 2015 sampai Mei 2016 konsumen yang belanja di Niagara Swalayan mengalami fluktuasi, pada bulan Desember konsumen yang belanja naik daripada 2 bulan yang sebelumnya, karena pada akhir bulan ini anak - anak sekolah sudah mulai liburan semester dan libur memasuki tahun baru, para pekerja kantoran pun juga libur memasuki tahun baru sehingga mereka yang tinggal di Bukittinggi pergi liburan di kota mereka sendiri dan yang berasal dari luar Bukittinggi pun berbondong - bondong pergi liburan ke Bukittinggi sehingga swalayan dan supermarket di Bukittinggi juga banyak mendapat kunjungan yang ikut mempengaruhi omset mereka. Tetapi mengalami penurunan pada 2 bulan selanjutnya, kemudian mengalami kenaikan kembali pada bulan April dan Mei 2016.

Menurut informasi yang di dapatkan dari manajemen Niagara Swalayan, Niagara Swalayan sampai sekarang bisa mengalami penjualan yang berkembang karena selain swalayan ini adalah swalayan yang pertama berdiri di kota Bukittinggi, adalah terutama faktor lokasi yang cukup dekat dengan pemukiman masyarakat dan kantor - kantor yang ada di kota Bukittinggi, di bandingkan sebelumnya yang berada di Pasar Atas, ketika masih berada di Pasar Atas manajemen kesulitan untuk memperluas tempat Niagara Swalayan, kemudian setelah pindah ke lokasi yang sekarang ini, baru Niagara Swalayan mengalami perkembangan yang cukup pesat, Niagara Swalayan beberapa tahun lalu sempat membuka Toko Buku Gramedia di lantai 3 tapi karena alasan kerugian operasional terpaksa di tutup, menurut manajemen hal ini disebabkan masyarakat Bukittinggi kurang mengetahui keberadaan Toko Buku Gramedia yang cukup jauh berada di atas yaitu di lantai 3 Niagara Swalayan ini, buku - buku yang jumlahnya masih sedikit di bandingkan Toko Sari Anggrek Bukittinggi, sehingga masyarakat kota Bukittinggi yang tahu pun kurang berminat untuk berkunjung ke Toko Buku Gramedia ini, karena alasan lokasi lantai 3 yang jauh di atas juga dan tidak fasilitas eskalator sampai sekarang lantai 3 tetap kosong, menurut manajemen Niagara Swalayan, pihak manajemen dalam beberapa tahun ini sudah mempertimbangkan untuk mengadakan eskalator, tapi saat ini belum juga terealisasikan. Niagara Swalayan pada tahun 2012 yang lalu sudah membuka cabang di kota Payakumbuh.

Pertumbuhan swalayan di Bukittinggi telah meningkatkan persaingan di antara perusahaan perusahaan ritel tersebut. Untuk dapat bertahan dan berkembang, sebuah swalayan perlu memahami perilaku konsumen agar mampu menimbulkan belanja ulang konsumen sehingga pada akhirnya dapat bersaing dengan swalayan lainnya. Untuk itu, swalayan perlu melakukan berbagai strategi agar dapat memberikan kepuasan pada konsumen dan mempengaruhi konsumen untuk melakukan belanja ulang pada swalayan tersebut.

Berdasarkan hasil penelitian terdahulu yang dilakukan oleh Tjoa dan Kimade, V. (2014) Retail mix secara simultan berpengaruh signifikan terhadap pembelian ulang. Store Design and Display, Communication mix, location, pricing dan Merchandise Assortments secara parsial berpengaruh signifikan terhadap pembelian ulang. Sedangkan Customer Service secara parsial tidak berpengaruh signifikan terhadap pembelian ulang.

Sedangkan hasil penelitian Andreas Wijaya, A. (2016), Store Atmosphere, Consumer Emotion And Purchase Decision berpengaruh positif dan signifikan terhadap Repurchase Intention. 
Dari uraian di atas penulis tertarik untuk meneliti pengaruh dari bauran ritel terhadap keputusan belanja ulang dengan judul: " Pengaruh Bauran Ritel Terhadap Keputusan Belanja Ulang di Niagara Swalayan Bukittinggi ”.

\section{Metodologi Penelitian}

Penelitian yang akan penulis lakukan termasuk ke dalam jenis penelitian kausal. Penentuan ukuran sampel dalam penelitian menggunakan rumus Cochran. Jumlah sampel dalam penelitian sebanyak 127 orang. Teknik pengambilan sampel menggunakan teknik accidental sampling. Jenis dan sumber data dalam penelitian ini menggunakan data primer dan data sekunder. Teknik pengumpulan data dalam penelitian ini dilakukan melalui kuesioner dan dokumentasi. Instrumen penelitian ini adalah menggunakan kuesioner dengan skala likert. Sebelum kuesioner digunakan, terlebih dahulu dilakukan uji validitas dan uji reliabilitas. Berdasarkan hasil uji validitas dan reliabilitas, dari total 57 pernyataan yang diajukan, semua pernyataan adalah valid dan reliabel sehingga tidak satu pernyataan pun yang dikeluarkan.Teknik analisis data dalam penelitian dengan mengunakan analisis jalur model trimming (path analysis trimming model).

\section{Hasil dan Pembahasan}

\subsection{Analisis Jalur Model Trimming}

Analisis Jalur Model Trimming adalah model yang digunakan untuk memperbaiki suatu model Struktur analisis jalur dengan cara mengeluarkan dari model variabel eksogen yang koefisien jalurnya tidak signifikan (Heise, David R., 1969; Al-Rasyid, H. dan Sitepu, 1994:12). Model trimming terjadi ketika koefisien jalur diuji secara keseluruhan ternyata ada variabel yang tidak signifikan, sehingga peneliti perlu memperbaiki model struktur analisis jalur yang telah dihipotesiskan.

Cara menggunakan model trimming yaitu menghitung ulang koefisien jalur tanpa menyertakan variabel eksogen yang koefisien jalurnya tidak signifikan. Dalam regresi linier terdapat 3 metode yang digunakan untuk membentuk model yaitu metode Stepwise, Forward dan Backward. Peneliti menggunakan metode backward yaitu pengujian dengan cara mundur, yaitu semua variabel $\mathrm{X}$ diregresikan dengan variabel Y. Pengeliminasian variabel X didasarkan pada nilai F (parsial) terkecil dan turut tidaknya variabel $\mathrm{X}$ pada model juga ditentukan oleh nilai $\mathrm{F}$ (tabel). Metode backward merupakan metode regresi yang baik karena dalam metode ini dijelaskan perilaku variabel respon dengan sebaik-baiknya dengan memilih variabel penjelas dari sekian banyak variabel penjelas yang tersedia dalam data.

Dari Uji Simultan Regresi Metode Backward Bauran Ritel Terhadap Keputusan Belanja Ulang dan Uji Parsial Regresi Metode Backward Bauran Ritel Terhadap Keputusan Belanja Ulang tergambarkan 4 model regresi yang dibentuk dengan cara mengeliminasi variabel independen yang terbukti memiliki nilai signifikasi F yang lebih besar dari 0,100. Model tersebut antara lain:

a. Model 1 yaitu Pengaruh simultan dan parsial Pelayanan pelanggan (X1), Desain \& tampilan toko $\left(\mathrm{X}_{2}\right)$, Bauran komunikasi $\left(\mathrm{X}_{3}\right)$, Lokasi $\left(\mathrm{X}_{4}\right)$, Keragaman barang $\left(\mathrm{X}_{5}\right)$, Penetapan harga $\left(\mathrm{X}_{6}\right)$ terhadap Keputusan Belanja Ulang konsumen (Y) menghasilkan nilai $F$ sebesar 21,137. Pengujian secara parsial menunjukkan bahwa variabel Keragaman barang $\left(\mathrm{X}_{5}\right)$ memiliki nilai $\mathrm{t}_{\text {hitung }}$ yang paling rendah yaitu 0,409 jauh dari batas normal yaitu lebih besar dari 1,95. Hal tersebut didukung pula dengan tingginya tingkat signifikansi yang mencapai angka 0,683 jauh dari batas normal yaitu lebih kecil atau sama dengan 0,05. Berdasarkan pengujian di atas maka pada model berikutnya variabel ini di eliminasi dari model penelitian.

b. Model 2 yaitu Pengaruh simultan dan parsial Pelayanan pelanggan $\left(\mathrm{X}_{1}\right)$, Desain \& tampilan toko $\left(\mathrm{X}_{2}\right)$, Bauran komunikasi $\left(\mathrm{X}_{3}\right)$, Lokasi $\left(\mathrm{X}_{4}\right)$, Penetapan harga $\left(\mathrm{X}_{6}\right)$ terhadap Keputusan Belanja Ulang konsumen (Y) menghasilkan nilai $\mathrm{F}$ sebesar 25,507. Pengujian secara parsial menunjukkan bahwa 
variabel Desain \& tampilan toko $\left(\mathrm{X}_{2}\right)$ memiliki nilai $\mathrm{t}_{\text {hitung }}$ yang paling rendah yaitu 0,936 jauh dari batas normal yaitu lebih besar dari 1,95. Hal tersebut didukung pula dengan tingginya tingkat signifikansi yang mencapai angka 0,351 jauh dari batas normal yaitu lebih kecil atau sama dengan 0,05. Berdasarkan pengujian di atas maka pada model berikutnya variabel ini di eliminasi dari model penelitian.

c. Model 3 yaitu Pengaruh simultan dan parsial Bauran komunikasi $\left(\mathrm{X}_{1}\right)$, Bauran komunikasi $\left(\mathrm{X}_{3}\right)$, Lokasi $\left(\mathrm{X}_{4}\right)$, Penetapan harga $\left(\mathrm{X}_{6}\right)$ terhadap Keputusan Belanja Ulang konsumen $(\mathrm{Y})$ menghasilkan nilai $F$ sebesar 31,697. Pengujian secara parsial menunjukkan bahwa variabel Lokasi $\left(\mathrm{X}_{4}\right)$ memiliki nilai t hitung yang paling rendah yaitu 1,127 jauh dari batas normal yaitu lebih besar dari 1,95 . Hal tersebut didukung pula dengan tingginya tingkat signifikansi yang mencapai angka 0,262 jauh dari batas normal yaitu lebih kecil atau sama dengan 0,05 . Berdasarkan pengujian di atas maka pada model berikutnya variabel ini di eliminasi dari model penelitian.

d. Model 4 yaitu Pengaruh simultan dan parsial Pelayanan pelanggan $\left(\mathrm{X}_{1}\right)$, Bauran komunikasi $\left(\mathrm{X}_{3}\right)$, Penetapan harga $\left(\mathrm{X}_{6}\right)$ terhadap Keputusan Belanja Ulang konsumen (Y) menghasilkan nilai $\mathrm{F}$ sebesar 41,747. Pengujian secara parsial menunjukkan bahwa seluruh variabel independen yang tersisa memiliki nilai $t_{\text {hitung }}$ yang lebih tinggi dari 1,95. Hal tersebut didukung pula dengan rendahnya tingkat signifikansi yang keseluruhannya lebih kecil dari 0,05 . Berdasarkan pengujian di atas maka pada model ini adalah model terbaik untuk memprediksi variabel yang mempengaruhi Keputusan Belanja Ulang konsumen.

Model penelitian yang terbentuk dari pembaharuan model adalah sebagai berikut:

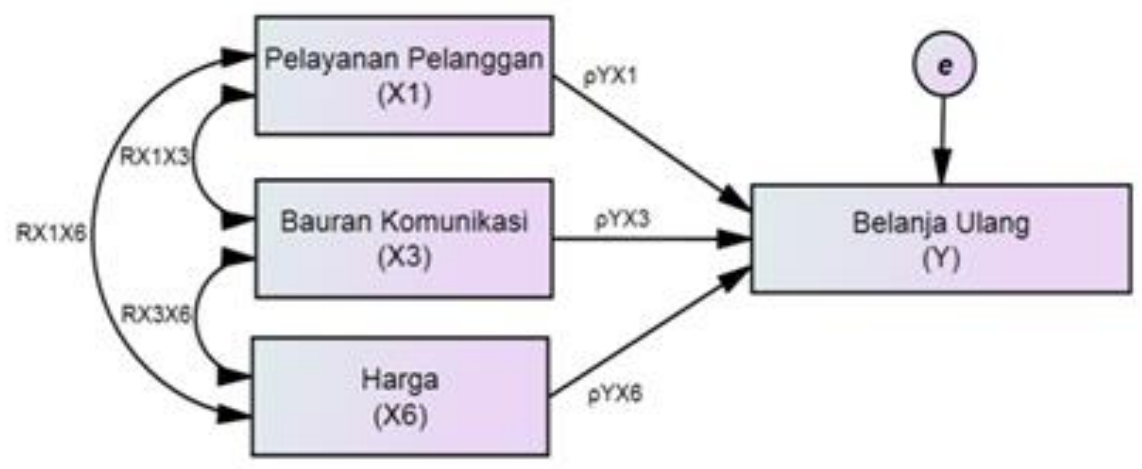

Gambar 1. Model untuk memprediksi variabel yang mempengaruhi Keputusan Belanja Ulang konsumen

\section{Hasil dan Pembahasan}

\subsection{Pengaruh Pelayanan Pelanggan $\left(X_{1}\right)$ terhadap Keputusan Belanja Ulang di Niagara Swalayan Bukittinggi (Y)}

Berdasarkan hasil analisis data diperoleh bahwa Pelayanan Pelanggan secara parsial memiliki pengaruh positif signifikan dalam mempengaruhi Keputusan belanja ulang di Niagara Swalayan Bukittinggi, hal ini bisa dilihat dari nilai $t_{\text {hitung }}$ yang lebih rendah bila dibandingkan dengan $t_{\text {tabel }}$, lebih lanjut alasan ini bisa di konfirmasi pula rendahnya nilai signifikansi yang kurang dari angka standar 0,05 .

Pengaruh langsung variabel ini terhadap variabel dependen sebesar 3,52\%, akan tetapi bila disertai dengan variabel dependen lainnya yang diuji dalam model penelitian ini, yaitu pengaruh tidak langsung yang sebesar 7,62\%, maka secara total pengaruh variabel ini mencapai angka $11,15 \%$. Angka ini tentunya cukup tinggi untuk diabaikan begitu saja oleh manajemen Niagara Swalayan. 
Hasil analisis deskriptif menunjukkan angka rerata variabel sebesar 76,2\% yang berarti cukup baik. Lebih lanjut hal ini mengindikasikan bahwa kualitas layanan dan layanan transaksi yang menjadi indikator penilaian variable ini cukup handal. Dengan membandingkan hasil analisis deskriptif, yang berada pada kisaran cukup baik, dan analisis jalur, yang cukup berarti pengaruh langsungnya, pada dasarnya manajemen Niagara Swalayan sangat perlu untuk mempertahankan dan memaksimalkan kualitas pelayanan terhadap pelanggannya yang tentunya diharapkan dapat meningkatkan pengaruh langsung variabel ini dalam mempengaruhi pelanggannya untuk melakukan pembelian ulang.

Menurut Zeithaml dan Bitner yang dikutip oleh Hurriyati, R (2005) orang/people adalah "People is human actor who play a part in service delivery and thus influence the buyer's perception: namely, the firm's personnel, the customers in the service environment". Penyedia jasa yang baik akan mempertinggi rasa kenyamanan terhadap pelanggan berkenaan dengan sebuah transaksi dan akan membuat transaksi tersebut sebuah pengalaman yang memuaskan.

Pelayanan dari personil/ karyawan (people) yang diberikan oleh toko berpengaruh terhadap persepsi konsumen terhadap toko tersebut sehingga untuk keberhasilan suatu toko harus memberikan berbagai macam jenis pelayanan terhadap konsumen serta memberikan pelayanan terbaik bagi konsumennya serta membangun sebuah komunitas tersendiri untuk mendapat tempat dibenak konsumen.

Secara umum manajemen Niagara Swalayan cukup baik dalam memberikan pelayanan pelanggan. Manajemen sadar bahwa konsumen membandingkan layanan yang diberikan oleh Niagara swalayan dengan layanan dari pengecer sejenis, sehingga memberikan pelayanan pelanggan "apa adanya" dan "tidak berbeda dengan yang lain" tidak akan memberikan kesan yang mendalam bagi pelanggannya, dan yang lebih buruk, dapat direspon oleh konsumen dengan beralih pada peritel lain yang lebih peduli kepada pelanggannya. Mengingat, variabel ini adalah satu-satunya dari sekian banyak variabel bauran ritel yang berbicara mengenai interaksi antar manusia, dan interaksi antar manusia bersifat unik dan menimbulkan kesan yang mendalam bagi manusia lainnya

\section{2. Pengaruh Bauran komunikasi $\left(X_{3}\right)$ terhadap Keputusan Belanja Ulang di Niagara Swalayan Bukittinggi (Y)}

Berdasarkan hasil analisis data diperoleh bahwa Bauran Komunikasi secara parsial memiliki pengaruh positif dan nyata (signifikan) dalam mempengaruhi Keputusan belanja ulang di Niagara Swalayan Bukittinggi, hal ini bisa dilihat dari nilai $t_{\text {hitung }}$ yang lebih tinggi bila dibandingkan dengan $t_{\text {tabel }}$, lebih lanjut alasan ini bisa di konfirmasi pula rendahnya nilai signifikansi dibanding dengan angka standar 0,05 .

Pengaruh langsung variabel ini terhadap variabel dependen mencapai angka $14.14 \%$, dan bila disertai dengan variabel dependen lainnya yang diuji dalam model penelitian ini, yaitu pengaruh tidak langsung yang sebesar $10.26 \%$, maka secara total pengaruh variabel ini mencapai angka $24,39 \%$. Variabel ini adalah keunggulan manajemen Niagara Swalayan yang diangggap oleh konsumen sebagai variabel yang paling mempengaruhi keputusan belanja ulang.

Hasil analisis deskriptif menunjukkan angka rerata variabel sebesar 75,8\% yang berarti cukup baik. Lebih lanjut hal ini mengindikasikan bahwa iklah, penjualan pribadi dan promosi penjualan yang menjadi indikator penilaian variabel ini tidak buruk tapi juga tidak istimewa. Dengan membandingkan hasil analisis deskriptif, yang berada pada kisaran cukup baik, dan analisis jalur, yang cukup besar pengaruh langsungnya, pada dasarnya manajemen Niagara Swalayan tertolong dengan keunggulan variabel yang mendorong perusahaan masih bisa berkompetisi di tengah ketatnya persaingan pada industri ini.

Menurut Berman, B. dan Evans, J. R. (2010), promosi didefinisikan sebagai: “Any communication by retailer that informs, persuade, and or reminds the target market". (Segala komunikasi oleh peritel yang menginformasikan, mengajak dan mengingatkan target pasar). Dari pengertian tersebut dapat disimpulkan promosi dengan cara memberitahu, membujuk dan mengingatkan konsumen agar mau membeli barang- barang yang dijual. 
Promosi yang dilakukan dalam kegiatan eceran biasanya untuk mengkomunikasikan informasi terhdap harga atau atribut lainnya dalam toko. Berkomunikasi dengan konsumen baik tentang barang yang dijual, harga yang diberikan ataupun penawaran-penawaran yang diberikan, komunikasi tersebut harus dibuat sekreatif mungkin sehingga dapat menarik konsumen dengan promosi yang kreatif dapat digunakan untuk menciptakan stimulus sehingga menuntun konsumen untuk melakukan keputusan dan pembelian.

Secara umum bauran komunikasi yang dilakukan manajemen Niagara Swalayan cukup efektif, meskipun masih bisa untuk ditingkatkan. Sepertinya manajemen Niagara Swalayan cukup sadar bahwa inti dari komunikasi ialah persamaan persepsi. Dan metode yang digunakan oleh manajemen Niagara Swalayan untuk memperkenalkan, mengingatkan dan membujuk konsumen untuk berinteraksi dengan pengecer cukup efektif dan mengena. Peritel sadar bahwa bauran komunikasi adalah salah satu komponen bauran ritel yang dapat mempengaruhi perilaku konsumen.

\section{3. Pengaruh Penetapan harga $\left(X_{6}\right)$ terhadap Keputusan Belanja Ulang di Niagara Swalayan (Y)}

Berdasarkan hasil analisis data diperoleh bahwa penetapan harga secara parsial memiliki pengaruh signifikan terhadap Keputusan belanja ulang di Niagara Swalayan Bukittinggi, hal ini bisa dilihat dari nilai $t_{\text {hitung }}$ yang lebih tinggi bila dibandingkan dengan $t_{\text {tabel }}$, lebih lanjut alasan ini bisa di konfirmasi pula rendahnya nilai signifikansi dibanding dengan angka standar 0,05 .

Pengaruh langsung variabel ini terhadap variabel dependen mencapai angka 7.13\%, dan bila disertai dengan variabel dependen lainnya yang diuji dalam model penelitian ini, yaitu pengaruh tidak langsung yang sebesar 7,72\%, maka secara total pengaruh variabel ini mencapai angka 14,85\%. Variabel ini adalah keunggulan ke dua dari manajemen Niagara Swalayan, setelah variabel bauran komunikasi, yang juga diangggap oleh konsumen sebagai variabel yang paling mempengaruhi keputusan belanja ulang.

Hasil analisis deskriptif menunjukkan angka rerata variabel sebesar 75,5\% yang berarti cukup baik. Lebih lanjut hal ini mengindikasikan bahwa harga barang dagangan yang kompetitif, penetapan harga ganjil dan kejelasan informasi harga yang menjadi indikator penilaian variabel ini tidak mengecewakan. Dengan membandingkan hasil analisis deskriptif, yang berada pada kisaran cukup baik, dan analisis jalur, yang cukup besar pengaruh langsungnya, pada dasarnya manajemen Niagara Swalayan tertolong dengan keunggulan variabel ini yang mendorong perusahaan masih bisa berkompetisi.

Secara umum penetapan harga yang dilakukan manajemen Niagara Swalayan cukup efektif, dan masih bisa untuk ditingkatkan. Sepertinya manajemen Niagara Swalayan cukup sadar bahwa harga berbanding lurus dengan permintaan. Disamping itu harga tetaplah menjadi daya tarik yang sangat dipertimbangkan ditengah ketidakstabilan ekonomi saat ini, disamping itu sebagian manusia akan berusaha untuk rasional dalam mempergunakan uangnya.

Menurut Berman, B. dan Evans, J. R. (2010) pricing adalah "a crucial strategic variable for a retailer because of its direct relationship with a firm's objective and its interaction with other retailing mix element". (variabel strategi yang penting bagi peritel karena berhubungan langsung dengan konsumen dan berinteraksi dengan bagian bauran ritel yang lain). Meskipun begitu strategi ini mesti dilakukan dengan bijak. Dalam situasi pemberian harga dalam pasar, terdapat banyak persaingan dan konsumen cenderung mencari harga yang paling rendah.

Dalam beberapa kasus, reaksi pesaing merubah harga menghasilkan perang harga, dimana pengecerpengecer menurunkan harga dibawah harga standar dan kadang dibawah biaya produksi untuk menarik konsumen. Dalam jangka perang harga tersebut sering menghasilkan keuntungan yang rendah, kerugian bahkan kebangkrutan bagi perusahaan. Oleh karena itu mengandalkan harga sebagai satu-satunya cara dalam bersaing adalah sangat berisiko tinggi. 


\section{4. Pengaruh Bauran Ritel $(X)$ terhadap Keputusan Belanja Ulang di Niagara Swalayan $(Y)$}

Berdasarkan hasil analisis data diketahui bahwa dari 6 variabel bauran ritel yang diuji dalam model penelitian ini hanya 3 variabel saja yang terbukti signifikan mempengaruhi Keputusan belanja Ulang di Niagara Swalayan, sedangkan 3 sisanya terbukti tidak memberikan pengaruh yang berarti. Oleh karena tujuan penelitian ini ialah mengkonstruk ulang model yang ideal dalam menjelaskan faktorfaktor yang mempengaruhi Keputusan belanja ulang di Niagara Swalayan, maka dilakukan pengujian regresi dengan metode backward, yaitu mengeliminasi varaibel yg tidak relevan sehingga terbentuk model baru yang paling cocok. 
Model terbaik yang dapat menjelaskan faktor-faktor yang mempengaruhi Keputusan belanja ulang di Niagara Swalayan terdiri dari Pelayanan Pelanggan (X1), Bauran Komunikasi (Xx) dan Penetapan Harga (X6). Hal ini diperkuat dengan hasil uji $\mathrm{F}$ yang menunjukkan nilai $\mathrm{F}$ hitung lebih tinggi dari nilai $\mathrm{F}$ tabel pada tingkat signifikan $5 \%$.

Pengaruh total, baik secara langsung dan tidak tidak langsung, dari variabel independen yang ada dalam model penelitian mencapai angka $0,504(50,4 \%)$, sebagaimana hasil uji koefisien determinasi (R2) yaitu sebesar 0,505 (50,5), selisih 0,001 dikarenakan perbedaan perhitungan perangkat lunak yang berbeda. Adapun sisanya sebesar $0,496(49,6 \%)$ di pengaruhi oleh variabel lain yang tidak di uji dalam model penelitian ini.

Perlu menjadi catatan bahwa belanja ulang konsumen adalah bagian dari perilaku konsumen yang dipengaruhi oleh 3 faktor utama yaitu faktor internal (kognisi dan afeksi), eksternal (Budaya, kelompok dan keluarga) dan strategi pemasaran (Bauran ritel). Maka pengaruh strategi pemasaran atau bauran ritel sebesar 50,4\% dalam penelitian ini adalah angka wajar, mengingat hanya 1 faktor utama yang menjadi fokus dari penelitian.

Meskipun begitu hasil pengujian ini menjelaskan bahwa ketiga variabel dalam bauran ritel adalah variabel yang handal dan signifikan dalam mempengaruhi keputusan belanja ulang di Niagara Swalayan Bukittinggi. Dengan demikian, temuan dari penelitian ini memperkuat dan mengkonfirmasi teori-teori beserta penelitian-penelitian terdahulu yang menyatakan bahwa bauran ritel mempengaruhi kepuasan, loyalitas dan belanja ulang.

Akhirnya, persaingan industri ritel khususnya dengan format swalayan, baik berukuran kecil maupun besar akan terus meningkat seiring bermunculannya peritel-peritel yang relatif modern, agresif dan bermodal besar seperti Lotte Mart, Giant, Carefour, Hypermart, Alfamart maupun Indomaret yang mana keseluruhannya muncul dengan penawaran dan kelebihan yang menarik dibanding dengan peritel-peritel tradisional.

Di sisi lain, kemajuan perekonomian yang mempengaruhi kehidupan masyarakat, peningkatan status sosial dan ekonomi masyarakat, yang mengakibatkan perubahan perilaku dan gaya hidup mereka, pada akhirnya mempengaruhi selera kepuasan terhadap suatu produk dan tempat belanja. Dan agar dapat bersaing, bertahan hidup, dan berkembang, maka peritel dituntut untuk mampu memberikan pelayanan berkualitas yang dapat memenuhi kebutuhan dan keinginan pelanggan melebihi para pesaingnya.

Untuk mengantisipasi hal tersebut tentunya perusahaan harus mengutamakan perluasan produk dan layanan yang berorientasi pada pelayanan yang mengutamakan kepuasan dan loyalitas. Mau tidak mau bauran pemasaran dan bauran ritel yang konvensional mulai mengalami perluasan dan penyesuaian yang cukup radikal, khususya di differensiasi pelayanan, karena differensiasi barang cukup sulit dilakukan dan sangat terbatas pengembangannya di bisnis ritel. Maka adalah wajar kiranya bila keunggulan barang bukanlah lagi menjadi satu-satunya keunggulan, begitu pula Lokasi bukan lagi menjadi halangan mengingat semakin beragamnya saluran pembelian baik secara offline maupun online .

\section{Kesimpulan}

Berdasarkan hasil penelitian maka dapat ditarik beberapa kesimpulan berikut ini: Dimensi bauran ritel yang terdiri dari Pelayanan pelanggan, Desain dan tampilan toko, Bauran komunikasi, Lokasi, Keragaman barang, dan Penetapan harga adalah konstruk yang handal dan signifikan dalam mempengaruhi keputusan belanja ulang di Niagara Swalayan Bukittinggi dengan pengaruh total mencapai angka 50,39\%. Adapun sisanya sebesar 49,61\% di pengaruhi oleh variabel lain yang tidak di uji dalam model penelitian ini. Pelayanan pelanggan berpengaruh signifikan terhadap Keputusan Belanja Ulang konsumen Niagara Swalayan Bukittinggi. Desain dan tampilan toko tidak berpengaruh signifikan terhadap keputusan belanja ulang di Niagara Swalayan Bukittinggi. Bauran komunikasi 
berpengaruh signifikan terhadap keputusan belanja ulang di Niagara Swalayan Bukittinggi. Lokasi tidak berpengaruh signifikan terhadap keputusan belanja ulang di Niagara Swalayan Bukittinggi. Keragaman barang tidak berpengaruh signifikan terhadap keputusan belanja ulang di Niagara Swalayan Bukittinggi. Penetapan harga berpengaruh signifikan terhadap keputusan belanja ulang di Niagara Swalayan Bukittinggi.

\section{Daftar Pustaka}

Al-Rasyid, H. dan Sitepu, 1994. Teknik Penarikan Sampel dan Penyusunan Skala. Bandung: Universitas Padjajaran.

Berman, B. \& Evans, J. R., 2010. Retail Management: A Strategic Approach (11th Ed.). New Jersey: Prentice Hall.

Dunne, Lusch, Griffith, 2002. Retaling (4th ed). New York. South-Western, A Division Of Thomsom Learning.

Gilbert, David, 2003, Retail Marketing Management 2nd Edition, Pearson Educated Limited : Edinburgh Gate, England

Heise, David R., 1969. Problem in Path Analysis and Causal Inference. In Edgar F. Borgaita. Editor. Sociological Methodology. San Francisco: Jossey- Bass Behavioral Science.

Hurriyati, R., 2005. Bauran Pemasaran dan Loyalitas Konsumen. Bandung: Alfabeta.

Kotler, P dan Keller, K. L., 2009. Manajemen Pemasaran. Terjemahan oleh Bob Sabran.Edisi 13.Jilid 1. Jakarta. Erlangga

Kotler, P dan Keller, K. L., 2009.Manajemen Pemasaran. Terjemahan oleh Bob Sabran.Edisi 13.Jilid 2. Jakarta. Erlangga

Levy, M. and Weitz, B. A., 2009. Retailling Management 7th edition. New York. Mc. Graw Hill/Irwin.

Tjoa dan Kimade, V., 2014. Pengaruh Retail Mix Terhadap Pembelian Ulang Konsumen Planet Sports Net Tunjungan Plaza Surabaya. Jurnal Strategi Pemasaran, Vol 2 (2014).

Wijaya, A, 2016. The Influence Of Store Atmosphere To Repurchase Intention Towards Consumer Emotion And Purchase Decision At Transmart Carrefour Cempaka Putih, Based In Central Jakarta. International Research Conference On Management And Business, 4th. 